\title{
A servidão voluntária e os impactos da (des)conexão nas atividades profissionais
}

O presente trabalho tem por objetivo demonstrar as causas e consequências da servidão inconsciente e involuntária dos profissionais em sua carreira. Uma problemática cada vez mais presente no cotidiano dos profissionais que abdicam de uma vida plena em troca de metas e resultados satisfatórios. O objeto central deste estudo consiste em compreender o fato gerador deste fenômeno para chamar a atenção a admitir, àqueles profissionais que ainda não admitiram que se encontram completamente consumidos pelo sistema. $O$ tema se justifica pela necessidade cada vez mais emergente pela busca por soluções, a fim de permitir aos trabalhadores desconectar-se das suas atividades laborais em seus momentos de descanso. Para isso, buscou-se no referencial teórico autores que desenvolveram teses sobre a conexão constante e involuntária em sua livre e auto coerção. Quanto a metodologia, aplicou-se uma pesquisa quantitativa baseada nos pontos de maior influência na vida do profissional atual, em relação a sua conexão constante e involuntária.

Palavras-chave: Servidão Voluntária; Mutabilidade nas relações profissionais; Impactos das novas relações.

\section{Voluntary service and the impacts of (dis)connection on professional activities}

\begin{abstract}
This work aims to demonstrate the causes and consequences of the professionals' unconscious and involuntary servitude in their career. A problem increasingly present in the daily lives of professionals who give up a full life in exchange for satisfactory goals and results. The central object of this study is to understand the triggering factor of this phenomenon to call attention to admit, those professionals who have not yet admitted that they are completely consumed by the system. The theme is justified by the increasingly emerging need for the search for solutions, in order to allow workers to disconnect from their work activities in their moments of rest. For this, the theoretical framework sought authors who developed theses on the constant and involuntary connection in their free and selfcoercion. As for the methodology, a quantitative research was applied based on the points of greatest influence in the life of the current professional, in relation to his constant and involuntary connection.
\end{abstract}

Keywords: Voluntary bondage; Mutability in professional relationships; Impacts of new relationships.

Topic: Direito do Trabalho e Processo do Trabalho

Reviewed anonymously in the process of blind peer

Vanessa Caroline Cardoso (it)

Universidade Regional do Noroeste do Estado do Rio Grande do Sul, Brasil http://lattes.cnpq.br/0899046368343300

http://orcid.org/0000-0001-9814-5280

vanessa.c.cardoso21@gmail.com
Received: 10/12/2019

Approved: $19 / 04 / 2020$
Referencing this:

CARDOSO, V. C.. A servidão voluntária e os impactos da (des)conexão nas atividades profissionais. Libro Legis, v.2, n.1, p.12-21, 2020. DOI: http://doi.org/10.6008/CBPC2674-6409.2020.001.0002 


\section{INTRODUÇÃO}

Tendo em vista a evolução social ocorrida nesse último século, propulsora de uma sociedade altamente competitiva, vislumbra-se uma mudança significativa entre o que vem assegurado na CLT (Consolidação das Leis do Trabalho), em termos de carga horária e qualidade de vida, e o que usualmente ocorre. Assim, se vê cada vez mais frequente a prática de abdicar de sua vida particular, abolir de sua rotina momentos de lazer com os entes próximos, a fim de vislumbrar atingir objetivos profissionais.

Nesses termos, a essência da lei trabalhista fundamenta-se em proteger a integridade física e emocional do indivíduo, impulsionando o cumprimento, a rigor, das prerrogativas estabelecidas, transmitindo assim uma falsa ideia de separação entre tempo a disposição do empregador e vida social do trabalhador.

A identificação do problema juntamente com a sua devida análise consiste no enfoque principal da pesquisa, de forma a avaliar os impactos da conexão indireta e involuntária ao trabalho, bem como as consequências que a conexão excessiva ao trabalho pode trazer à vida pessoal do trabalhador. Além disso, visa demonstrar o fundamento do compromisso excessivo, que de forma inconsciente mantêm-nos constantemente atrelados à vida profissional, impedindo a desconexão das preocupações no trabalho.

As tecnologias, quando utilizadas de forma adequada, proporcionam momentos de entretenimento, cultura e informação. Porém, quando a tecnologia rouba o tempo de descanso garantido pela CLT, elas transformam-se em grande obstáculo ao descanso do funcionário. O meio físico se tornou um mero detalhe na operação, e fez com que o ato de sair da empresa para desconectar-se seja substituído pelo constantemente conectado.

Este trabalho retrata a importância que o homem dá ao seu trabalho junto a necessidade de capital, com isso, a crença de que todos os indivíduos ativos no mercado de trabalho, indireta e involuntariamente estão consumidos pela servidão voluntária.

\section{DISCUSSÃO TEÓRICA}

\section{Breve referenciação histórica da servidão voluntária}

Voltando-se mais especificamente à origem do termo, destaca-se o trabalho de Étienne de La Boétie, no século XVI. O pensador, com base na estrutura do sistema de governo presente na época, passou a analisar a temática, concentrando o seu trabalho, mais especificamente, ao estudo do controle governamental no comando de milhares de homens de diversas cidades.

Assim, a ideia de que uma única pessoa seria capaz de dominar e ser temido por milhares de cidadãos Ihe garantiu o pontapé inicial para o estudo, atingindo uma maior amplitude ao termo servidão voluntária. Em outras palavras, Étienne objetivou compreender a razão existente por detrás dessa submissão, como bem refere (BOÉTIE, 2017): "nunca se pode garantir que seja bom, pois tem sempre o poder de ser mal quando desejar".

Ao contrário do que o termo "servidão" leva a crer, a tese de La Boétie coloca o homem como servo 
voluntário, mesmo que, por vezes não haja coerção. Em suas palavras, explana:

É o próprio povo que se escraviza e se suicida quando, podendo escolher entre ser submisso ou ser livre, renuncia à liberdade e aceita o jugo; quando consente com seu sofrimento, ou melhor, a procura. (BOÉTIE, 2017)

Além disso, complementa o autor (BOÉTIE, 2009): “como imaginar de outro modo que um só indivíduo ou um pequeno grupo obrigue os demais cidadãos a obedecer com tanta submissão".

Neste cenário de dominação em massa, Étienne destaca que por haver tanta vontade em ser servo o povo não enxergava a oportunidade em ser livre. Para Boétie (2009), a liberdade está na união das equipes, e elas "têm a capacidade de se desdobrarem, mudar de foco, se dissolver rapidamente e de criar resultados que seus membros realmente desejam.

Bastaria um olhar diferente do grupo, uma vontade em não mais servir e sim ser dono da sua própria existência, caso houvesse essa revolta dos servos, o poder centralizador seria extinto, pois perderia a capacidade de assumir o controle da vida do seu povo.

Portanto, era uma servidão voluntária pois os servos seguiam o sistema de governo presente na época sem se rebelar. Aceitavam porque acreditavam que teriam benefícios, e que, principalmente, o sistema não poderia ser diferente. Ou seja, desejavam segui-lo, mesmo que inconscientemente.

O significado atual do termo, explanado no presente trabalho, tem fundamento na servidão voluntária presente na antiguidade. Não se consiste em uma pressão em si, mas em seguir o sistema sem rebelar-se, seguir o sistema capitalista por vontade própria, para não perder espaço e buscar crescimento.

\section{A Auto cobrança inconsciente como propulsor da servidão voluntária}

No cenário atual, percebemos o mercado de trabalho cada vez mais competitivo e limitado, passando por mudanças frequentes que ocorrem instantaneamente. Essas mudanças pressionam os profissionais ao aperfeiçoamento constante para que assim acompanhem a constante evolução. Esta exigência ocorre de forma gradual e indireta, partindo do próprio indivíduo quando esse percebe o crescimento do número de pessoas competentes concorrendo a seus postos de trabalho.

Partindo desse ponto, tal acontecimento proporciona ao desenvolvimento de uma autocobrança pessoal, que impede o indivíduo de romper com o seu vínculo profissional nos momentos de descanso, e, ainda, que restabeleça a sua vida pessoal e social.

Nesse sentido, Janiro (2016) desenvolve a sua linha de raciocínio partindo do pressuposto de que esse fenômeno pode ter a sua origem na infância, mais especificamente nas situações em que as crianças são incentivadas a competir umas com as outras, o que poderá ocasionar transtornos futuros inconscientes.

Muitas vezes essa cobrança é estimulada desde bem cedo, ainda na infância, quando as famílias, educadores ou pessoas próximas comparam as crianças umas com as outras, exigem desempenhos sempre melhores em relação aos coleguinhas ou rotulam os pequenos por conta de suas dificuldades.

Complementa, ainda, que muitas vezes essas crianças desenvolvem um sentimento de rejeição, a partir da crença de que somente poderão ser amadas quando destacarem-se e forem taxadas como sendo as melhores naquilo que fazem. 
Nesse mesmo sentido, Lucas de Melo Prado apresenta uma interligação entre a obra de Étienne de La Boétie e a do filosofo sul-coreano Byung-Chul Han. As obras se comunicam no sentido em que Étienne traz a teoria da livre submissão, enquanto Han (2017) transcorre sobre a tomada de iniciativa do indivíduo impulsionado pelo seu meio, e assim refere:

[...] no lugar de proibição, mandamento ou lei, entram projeto, iniciativa e motivação. A sociedade disciplinar ainda está dominada pelo não. Sua negatividade gera loucos e delinquentes. A sociedade do desempenho, ao contrário, produz depressivos e fracassados.

A crença proposta por Han (2017) é de que aos objetivos do trabalhador tudo é possível, equiparando-o a uma máquina realizadora de metas. Para aqueles inseridos em um sistema cuja engrenagem para o sucesso gira a cada objetivo alcançado, essa pressão por resultados ocasiona um transtorno neural, uma autocobrança que não parte do outro, mas que é intrínseca do próprio ser. Por falta de repouso, segundo Nietzsche (2004): "nossa civilização caminha para uma nova barbárie, em nenhuma outra época os ativos, isto é, os inquietos, valeram tanto".

Ademais, como consequência, a sociedade produz até a exaustão e mesmo esgotada continua a produzir. Se uma meta é alcançada, será brevemente comemorada e em seguida substituída por outra. Sem perceber, o homem abdica de uma vida plena para obter, em contrapartida, uma vida repleta de metas atingidas, mas nem ao menos comemoradas, tornando-o vulnerável a frustração. O resultado vem expresso em pessoas deprimidas, que esperam encontrar em estimulantes e medicamentos a continuação de sua produção.

Nesse diapasão, um autor capta o sentido da sociedade do cansaço:

Estamos exaustos e correndo. Exaustos e correndo. Exaustos e correndo. E a má notícia é que continuaremos exaustos e correndo, porque exaustos e correndo virou a condição humana dessa época. E já percebemos que essa condição humana um corpo humano não aguenta. $O$ corpo então virou um atrapalho, um apêndice incômodo, um não dá conta que adoece, fica ansioso, deprime, entra em pânico. E assim dopamos esse corpo falho que se contorce ao ser submetido a uma velocidade não humana. Viramos exaustos e correndo e dopados. Porque só dopados para continuar exaustos e correndo.

Em consonância, Han (2017) define este "doping" como "neuro-enhancement" (melhoramento cognitivo), entendendo o ato de não se dopar como uma irresponsabilidade, por significar a perda de desempenho e permissão a uma maior suscetibilidade ao erro. Corresponde a mais um reflexo da sociedade do desempenho, é o que coloca a prova os impactos dessa aceleração constante a que se submete. A razão que motiva a sociedade esgotada a continuar movendo-se em busca de novos resultados, sem satisfazer-se com aqueles até então obtidos.

\section{Sociedade da cobiça}

Na sociedade contemporânea, o hábito de estar constantemente conectado tornou-se característica intrínseca à era vivenciada. Porém, o ato de estar inserido em mídias sociais transmite uma percepção falsa de mundo. Isto porque, é possível acompanhar a vida pessoal de qualquer pessoa a nível universal, como explica Bauman (2007): "na era da informação, a invisibilidade é equivalente à morte". Tornar-se visivelmente ativo, ser notado e invejado por aquilo que usufrui, traz consigo um impacto negativo ao público 
que consome este conteúdo, gerando assim um conceito de felicidade que falsamente lhe é apresentado.

Reforçando a tese, Han (2017) explana:

Na sociedade expositiva cada sujeito é seu próprio objeto-propaganda; tudo se mensura em seu valor expositivo. A sociedade exposta é uma sociedade pornográfica, tudo está voltado para fora, desvelado, despido, exposto para fora.

A exposição incessante tem um objetivo, vender a ideia que está sendo transmitida, e, assim, consumi-la. Mas engana-se aquele que sonha com o consumismo antes de se tornar refém do sistema. Bauman (2007) refere que vivemos em uma sociedade extremamente consumista e que "ninguém pode se tornar sujeito sem primeiro virar mercadoria". Em outras palavras, antes mesmo de se usufruir dos resultados obtidos, deve-se, incessantemente, fazer a engrenagem do capital girar de forma positiva para com as partes interessadas.

Em suma, o trabalho virou uma obsessão, já que apenas com resultados positivos no trabalho é possível obter conforto e um status social capaz de proporcionar fama e dinheiro. Em paralelo a isso, Han (2017) explicita: “o hipercapitalimo transforma todas as relações humanas em relações comerciais. Ele arranca a dignidade do ser humano, substituindo-a completamente pelo valor de mercado". Por consequência, isto torna o ser humano um objetivo de fácil manipulação quando o que está em jogo é conforto e ostentação.

A era da informação e do desempenho chegou de forma avassaladora consumindo os indivíduos inseridos no meio. O mundo capitalista não permite ao indivíduo preocupar-se com a sua integridade física e emocional, pois a maior preocupação é produzir e gerar resultados aos negócios, não resta tempo para outras preocupações.

Estar constantemente interligado proporciona uma série de resultados positivos quando utilizado da forma adequada. A facilidade à informação e o acesso rápido a diversas plataformas permite encontrar soluções instantaneamente, detendo pouco tempo de procura em rede. Portanto, hoje é possível "carregar o mundo nas mãos" através de smartphones cada vez mais sofisticados.

A auto cobrança, quando em nível exacerbado, pode estimular uma carga excessiva de informações, que acumuladas, podem originar maiores danos à performance do indivíduo. Nesse sentido, Han (2017) refere:

A memória de hoje se caracteriza por um amontoado de lixo e de dados em 'lojas de sucata' e 'armazéns' entulhados de massa e de uma variedade de imagens possíveis e imagináveis, totalmente desorganizados, malconservados, cheio de símbolos desgastados.

Dessa forma, o excesso de informação não é sinônimo de estar bem informado. Na era de acesso fácil a tecnologia, postar e compartilhar se tornou um passa tempo, e isso é perigoso para quem recebe, pois gera muitas dúvidas sobre a veracidade dos fatos. Ainda, além de acúmulo de informações estamos expostos, mais um agravante é o acúmulo de lixo digital presente em comunidades diversas, como caixas de e-mails e páginas no Facebook.

Para que uma onda de informação não acabe nos afundando deve ser organizada de forma a otimizar tempo, tornando o ato de fazer uma pesquisa uma tarefa prática e confiável.

Os status, os rótulos e as premiações são cada vez mais cobiçados na atualidade. As consequências 
que um possível fracasso profissional pode trazer impulsiona a busca incessante pelo sucesso profissional nas organizações. Por este motivo é que "não é permitido" se desligar, não se pode perder a oportunidade de aprender novas ferramentas ou formas que agreguem valor a si ou ao seu negócio. $\mathrm{O}$ acúmulo de informações gera carga tão alta de conteúdo que o indivíduo entra em uma espécie de transtorno neural, tendo o efeito reverso do que inicialmente se estava buscando, prejudicando o seu desempenho. É, segundo Han (2017), um "agressor e vitima ao mesmo tempo".

\section{Limites da jornada de trabalho e o direito à desconexão}

Foi muito longa a trajetória até que se conquistasse a limitação da jornada de trabalho, resguardada pela permissão legal aos intervalos de descanso e ao direito do trabalhador de desconectar-se do trabalho enquanto lá não estiver. Porém, todas essas garantias sobrevieram em um período marcado pela Revolução Industrial, foram frutos de movimentações sociais e da busca incessante de quem trabalhava mais de 14 horas por dia em condições precárias e insalubres. Constatada a série danos decorrentes dessa jornada de trabalho excessiva, apurou-se a urgência por alterações no regime de trabalho e nas condições de trabalho, momento muito significativo para a existência dos direitos atuais.

Outro fator importante para essas conquistas trabalhistas foi a afirmação de Tratados Internacionais que sobrelevam os direitos fundamentais a um patamar muito acima do que os demais defendidos em outras fontes legislativas, em especial a trabalhista. Asseguram que tais garantias se encontram inerentes à dignidade humana, portanto invioláveis e indispensáveis para o bem-estar físico, psicológico e social humanos.

Com o passar dos anos, porém, foi a vez da Revolução Tecnológica, que acabou por transformar todas as relações, trazendo um caráter ainda mais dinâmico e exponencial ao mercado de consumo, e assim, consequentemente, também às relações de trabalho. Impulsionados pelo progresso tecnológico, os equipamentos de comunicação têm sido utilizados de forma intensificada, possibilitando inclusive a conexão do trabalhador com o seu trabalho em tempo integral. Essa realidade acaba ameaçando o direito à limitação da jornada de trabalho e o direito à desconexão alcançados nos últimos anos. De acordo com Castells (1999):

Uma revolução tecnológica concentrada nas tecnologias da informação começou a remodelar a base material da sociedade em ritmos acelerados. Economias por todo o mundo passaram a manter interdependência global, apresentando uma nova forma de relação entre a economia, o Estado e a sociedade.

Para que isso seja amenizado a desconexão ao trabalho permitirá ao empregado usar aquele período concedido a título de intervalos de descanso ou de férias para atividades pessoais, sociais e que não estejam relacionadas ao trabalho. Em resumo, caracteriza-se como o direito de desligar-se do trabalho e deter algum tempo para atividades não laborais e de não comprometer seus horários livres com pensamentos e incômodos que remetam ao trabalho.

O direito de desconectar-se do trabalho, pelas palavras de Maior (2003):

É de trabalhar menos, até o nível necessário a preservação da vida privada e da saúde, considerando-se essencial esta preocupação (de se desligar, concretamente, do trabalho) exatamente por conta das características deste mundo do trabalho marcado pela evolução 
da tecnologia, pela deificação do mercado e pelo atendimento, em primeiro plano, das exigências do consumo.

Deste modo, o trabalhador acaba ficando conectado por mais tempo ao seu trabalho, pois a empresa pode estender a jornada de seu empregado ao contatá-lo através de meios eletrônicos em seus momentos de descanso. O reconhecimento e aplicação deste direito visam resguardar não só a saúde do empregado, como também o direito ao lazer (FERRER, 2015). Inclui também, Maior (2003) da desconexão:

Ao falar da desconexão faz-se um paralelo entre a tecnologia, que é fator determinante da vida moderna, e o trabalho humano, com o objetivo de vislumbrar um direito do homem de não trabalhar ou, como dito, metaforicamente, o direito a se desconectar do trabalho. Mas, esta preocupação é em si mesma um paradoxo, revelando, como dito as contradições que marcam o nosso "mundo do trabalho.

Portanto, seguindo a linha de Cassar (2009), o direito à desconexão ou ao não trabalho perpassa por quatro elementos: o estresse enfrentado pelo trabalhador por ter que se manter o tempo todo atualizado, causando além da fadiga mental, as doenças relacionadas ao trabalho, o direito ao descanso sem reflexos do trabalho, o direito à privacidade e intimidade, direito a trabalhar menos, ou ao limite de trabalho.

\section{Análise e interpretação de dados}

No âmbito metodológico, o artigo apresenta a realização de uma pesquisa que tem como seu principal objetivo tornar lúcido a realidade dos profissionais no mercado de trabalho atual. A pesquisa se fez presente de caráter quantitativo pois buscou-se trazer de forma estatística o índice de profissionais que estão colocando o trabalho como fonte geradora de prazer, atrelando sua felicidade aos resultados obtidos na empresa.

Para que fosse possível a coleta de dados, realizou-se uma pesquisa via mídia digital com os colaboradores de uma empresa localizada na cidade de Santo Cristo, estes através de seus smartphones responderam o questionário de onde mais lhe fossem convenientes. O questionário esteve disponível aos colaboradores no período de maio de 2019 a junho de 2019. Após realizada a pesquisa vários pontos tomados como críticos no decorrer deste estudo se tornando visíveis.

Foi possível identificar o quanto o trabalho está consumindo os momentos de 'desconexão' dos trabalhadores. A pergunta visa lustrar justamente esse sentimento de conexão constante, mesmo estão longe do local, mesmo fazendo uso dos intervalos entre jornadas, as tarefas que ficaram pendentes ou não foram bem-sucedidas ainda rompem as paredes da empresa e se juntam aos profissionais em seus momentos de lazer.

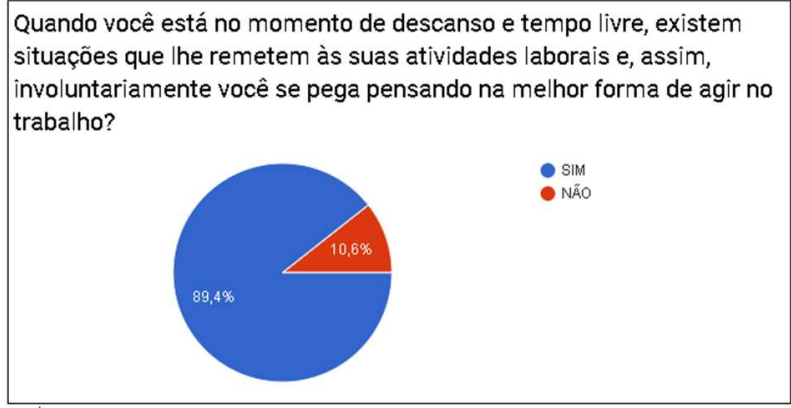

Ilustração 1

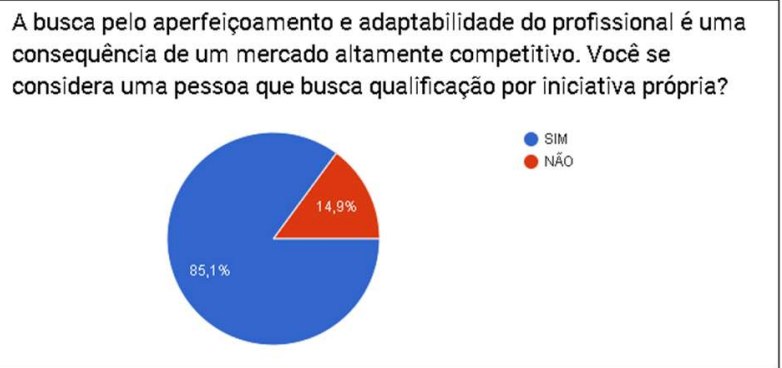

Ilustração 2 
Neste cenário foi possível constatar que $89,4 \%$ dos profissionais que responderam à pesquisa afirmam que indiferente se estão à disposição da empresa, sua mente ainda continua trabalhando, seu corpo ainda sofre as consequências do que não foi devidamente realizado, diante disso, as leis trabalhistas nada podem fazer, não é o empregador que exige, é o empregado quem faz.

A segunda questão reforça mais uma vez a necessidade que o indivíduo sente de se auto analisar, de se situar no mercado e vislumbrar sua profissão no futuro. Conforme dados apresentados $85,1 \%$ dos profissionais buscam por iniciativa própria se capacitar, o que para a empresa pode ser um fator de risco. Aquele trabalhador que busca desenvolvimento técnico e intelectual jamais se permitirá ser por muito tempo apenas mais uma peça que gira a engrenagem, aquele que busca sua autocapacitação logo irá querer colher os frutos do seu esforço.

Para as empresas que possuem muitos destes profissionais podem estar jogando contra si mesma, profissionais altamente eficazes e empenhados numa organização engessada de poucas oportunidades serão geradoras de frustração. Assim, como o mercado está cada vez mais cheio destes tipos de profissionais, os gestores da área de recursos humanos deverão buscar ferramentas para encarar estes desafios.
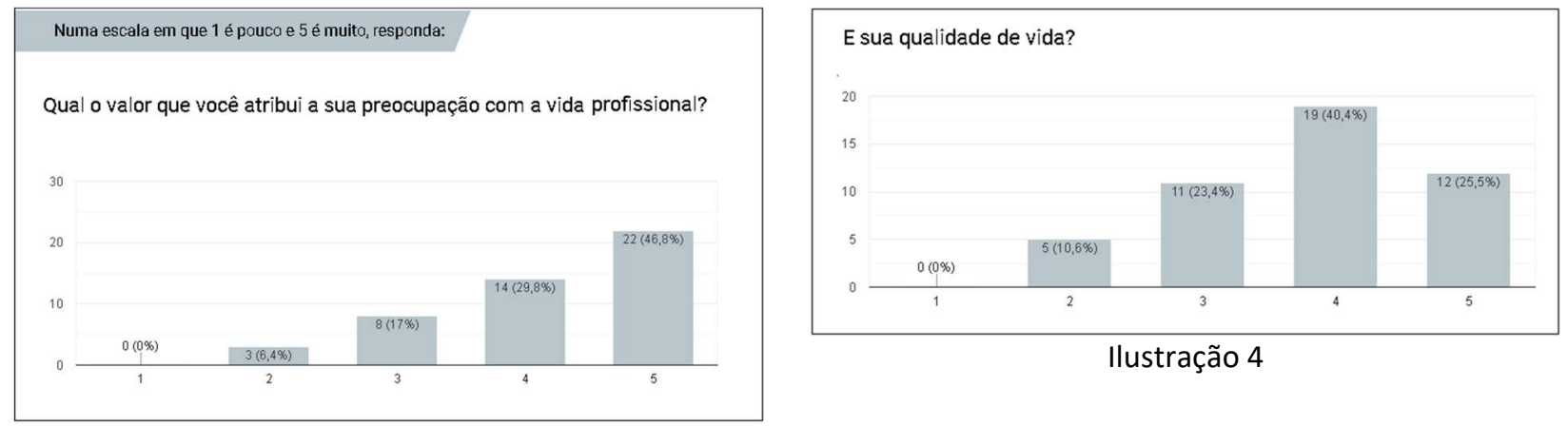

Ilustração 3

As questões 3 (três) e 4 (quatro) se complementam no sentido em que é possível notar que ainda existe um certo equilíbrio entre vida profissional e qualidade de vida. Porém pegando a nota máximo como referência, enquanto $46,8 \%$ das pessoas preocupam-se excessivamente com sua vida profissional apenas $25,5 \%$ buscando alta qualidade de vida. Este dado pode se tornar preocupante no sentido em que estar vivendo o trabalho pode se tornar um transtorno para saúde física e psíquica dos trabalhadores.

No geral a nota 4 (quatro) tanto para preocupação com a qualidade de vida quanto com a vida profissional se mostrou bastante presente, podendo-se encarar de uma forma otimista pois além de estarem buscando desenvolvimento técnico as pessoas estão preocupando-se em manter uma vida plena. Entretanto, não exatamente o que o resultado da próxima questão demonstrou:

Aproximadamente $70 \%$ das pessoas por vezes abrem mão de estarem na companhia de famílias e amigos para momentos de descontração pois encontram-se completamente esgotadas. Por vezes situações geradas no local de trabalho geram impactos diretos no bem-estar do indivíduo, ao contrário do que a questão 1 demonstrou em que em torno de $90 \%$ dos profissionais se pegam pensando nas suas atividades diárias, aqui, $68,1 \%$ dos trabalhadores não se permitem viver uma vida fora pois carregaram consigo toda a carga negativa gerada no âmbito profissional. O que demonstra a próxima questão é que quando as pessoas 
conseguem sair, conseguem 'desconectar-se' e reúnem-se na companhia de colegas e amigos, eis que o tema 'trabalho' novamente rouba a cena.

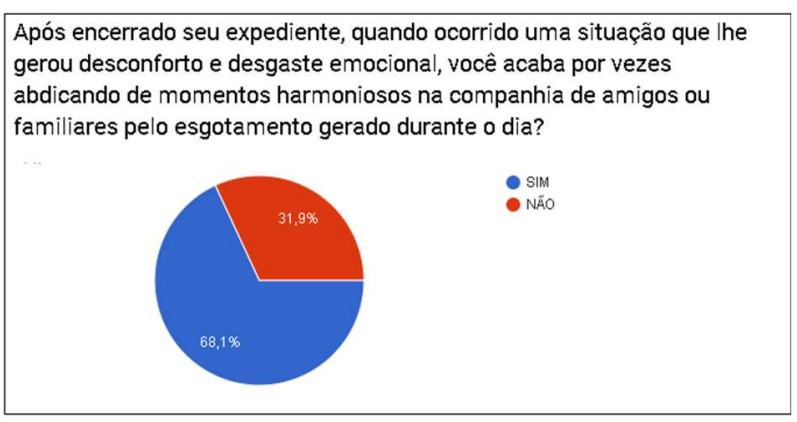

Ilustração 5

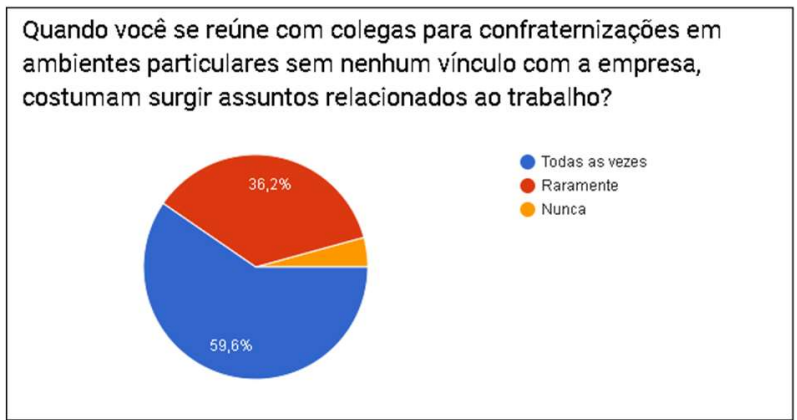

Ilustração 6

Observa-se que $95,8 \%$ das pessoas que responderam à pesquisa reconheceram que compartilham de situações ocorridas no trabalho com os presentes no evento, deste número que já é muito significativo $59,6 \%$ das pessoas afirma que temas relacionados ao trabalho sempre se fazem presente. Apenas $4,2 \%$ das pessoas afirma que conseguem desconectar-se da sua vida profissional a disfrutam do seu momento de lazer.

Para encerrar o questionário, aplicou-se a questão que envolve o maior responsável por tudo que foi apresentado até aqui, a tecnologia. A tecnologia tomou conta de tudo e de todos, a distância que certa vez era um limitador hoje não passa de um mero detalhe quando se trata de vida profissional. Acesso rápido, fácil e ilimitado. Estes três pilares tornaram a tecnologia um meio de comunicação altamente eficaz, produtivo é verdade, entretanto, torna mais um meio para as pessoas cercarem-se de trabalho.

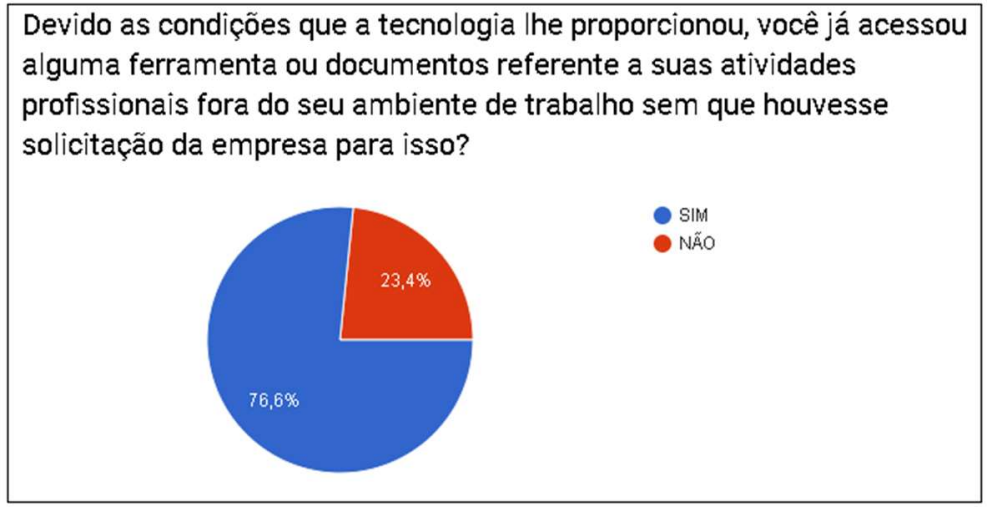

Ilustração 7

O objetivo principal desta questão é demonstrar como a tecnologia pode ser um vilão para a qualidade de vida dos profissionais. As leis trabalhistas existem para proteger o trabalhador na medida em que proíbe o empregador de exigir do funcionário mais tempo a disposição da empresa, mas aí encontra-se a auto sabotagem do profissional e mais uma vez o termo servidão voluntário se faz presente.

A pesquisa enfatiza que o profissional está fora do seu ambiente de trabalho e o empregador não está Ihe solicitando nada. Com o desejo ao sucesso profissional atrelado a concorrência entre profissionais altamente qualificados, utilizar a tecnologia se tornou um aliado quando se busca alta performance, quando se abre mão da qualidade de vida para viver e colher os frutos de uma carreira bem-sucedida, não cogitar os impactos dessa conexão constante pode gerar danos catastróficos a vida destes profissionais. 


\section{CONCLUSÕES}

Após o encerramento deste estudo, foi possível constatar-se que o trabalhador na sua essência age involuntariamente em prol da sua vida profissional. Por vezes, não haver está autorreflexão não permitirá que as pessoas busquem se desconectar. O fato de existir um mercado altamente competitivo e rápido, observa-se as oportunidades cada vez mais limitadas tornar-se um trabalhador merecedor desta oportunidade tornou os trabalhadores irracionais, a busca pelo resultado está à frente da sua própria saúde, do seu próprio bem-estar e em consequência aos que do meio fazem parte.

Seja qual for o ramo de atividade, em todos os setores será possível encontrar profissionais de alto desempenho e baixa auto realização, na maioria das vezes eles são a mesma pessoa. Profissionais de alto desempenho não produzem felicidade, produzem resultados, resultado geram capital e deste ele toma posse, porém os resultados gerados não são apenas positivos, muito tempo de conforto e lazer foi necessário sacrificar para que ele se tornasse peça fundamental para a empresa.

Como foi possível constatar mediante a realização da pesquisa, os trabalhadores não estão se permitindo desconectar. Por mais que haja por parte dos gestores e da CLT (Consolidação das Leis do Trabalho) uma preocupação com carga excessiva, são os profissionais que estão criando artimanhas que na maioria das vezes via digital, para prepararem-se para produzirem ainda mais. Isso derruba qualquer hipótese de controle do empregador, tornando impossível proibir que o profissional por iniciativa própria busque fonte de resultados para o seu negócio.

Para indicador de qualidade de vida do profissional, o presente trabalho sugere ao gestor utilizar a ferramenta FIB. Com ela, será possível identificar lacunas na vida dos trabalhadores, se diante destes dados apresentados a empresa realizar ações que preencham estes espaços e que o trabalhador deixa de ser ver como uma máquina realizadora de metas e passe a se ver como um ser humano, que busca sim sucesso profissional, mas antes de mais nada busca uma vida repleta de autorrealizações pessoais.

\section{REFERÊNCIAS}

BAUMAN, Z.. Tempos Líquidos. Rio de Janeiro: Zahar, 2007.

BOÉTIE, E.. Discurso da servidão voluntária. 2 ed. São Paulo; Martin Claret, 2009.

BOÉTIE, E.. Discurso sobre a servidão voluntária. São Paulo: Edipro, 2017.

CASSAR, V. B.. Direito do Trabalho. 3 ed. Rio de Janeiro: Impetus, 2009.

CASTELLS, M.. A Sociedade em Rede. 6 ed. São Paulo: Paz e Terra, 1999.

FERRER, D. S.. O direito à desconexão do trabalho: uma proposta conceitual a partir da filosofia existencialista e 'o estrangeiro' de Albert Camus. Revista Diálogos do Direito,
Cachoeirinha, v.5, n.9, 2015. Dol: http://dx.doi.org/10.17793/rdd.v5i9

HAN, B.-C.. Sociedade da transparência. Rio de Janeiro: Vozes, 2017.

HAN, B.-C.. Sociedade do cansaço. Rio de Janeiro: Vozes, 2017.

JANIRO, A. C.. Auto cobrança excessiva é geradora de frustração. 2016.

MAIOR, J. L. S.. Do direito à desconexão do trabalho. Campinas: Revista do Tribunal Regional do Trabalho da 15a Região, 2003.

NIETZSCHE, F. W.. Humano, demasiado humano. São Paulo: Companhia de Bolso, 2004.

A CBPC - Companhia Brasileira de Produção Científica (CNPJ: 11.221.422/0001-03) detém os direitos materiais desta publicação. Os direitos referem-se à publicação do trabalho em qualquer parte do mundo, incluindo os direitos às renovações, expansões e disseminações da contribuição, bem como outros direitos subsidiários. Todos os trabalhos publicados eletronicamente poderão posteriormente ser publicados em coletâneas impressas sob coordenação da Sapientiae Publishing, da Companhia Brasileira de Produção Científica e seus parceiros autorizados. Os (as) autores (as) preservam os direitos autorais, mas não têm permissão para a publicação da contribuição em outro meio, impresso ou digital, em português ou em tradução. 